\title{
An Investigation into the Use of Cohesive Devices in Second Language Writings
}

\author{
Mohsen Ghasemi \\ Department of English Language and Literature, Ferdowsi University of Mashad, Iran
}

\begin{abstract}
As far as the communicative nature of writing is concerned, cohesion is regarded as an essential textual component both in creating organized texts and rendering the content comprehensible to the reader. Many researchers have explored the connection between the use of cohesive devices (CDs) and the quality of the writing. To gain more insight into this area, this study reviewed some studies focusing on the use of CDs and the relationship between the number of CDs and writing quality. The analysis of collected data from different EFL/ESL researchers has shown that the learners were able to use various CDs in their writings. Additionally, the study highlighted some of the cohesive problems in writing and the possible pedagogical implications for teachers. The purpose of the present study is to investigate CDs used in different genres composed by learners from around the globe and the relationship between the use of CDs and quality of their essays. The findings also provide insight into the abilities of native and nonnative writers to convey their ideas into written forms. The results of this research will provide us with insights into the general pattern of CDs in EFL/ESL learners' academic and nonacademic writing. This would help to identify students' problems in using CDs, for instance, overuse or underuse of certain categories, and, thereby, modify teaching writing and incorporate a more precise plan for teaching the appropriate use of CDs.
\end{abstract}

Index Terms - cohesive devices, cohesion, coherence, writing genres, writing quality

\section{INTRODUCTION}

Undoubtedly writing as one of the second language skills is really arduous. According to Richards and Renandya (2002) the difficulty emanates both from generating and organizing ideas and translating these ideas into readable text. Halliday and Hasan $(1976,1989)$ believed that cohesion and coherence, as the two important textual elements have long been recognized as important features of good writing. So, language learners indispensably need to write coherent and cohesive texts if they wish to prove to be qualified English writers, whether they are EFL or ESL learners. This is the case especially in EFL contexts in which there is much little direct exposure to English. Recently, researchers the way in which EFL/ESL learners actually write and what problems they usually encounter in their writing have attracted considerable attention. Research in the field of cohesion and coherence in the English texts has been increasingly done since the publication of Cohesion in English (Halliday \& Hasan, 1976). L2 writers should always keep in their mind that readers would not be able to trace the ideas in any written text unless they signal the interconnections of the preceding and following pieces of message through contextual clues.

A text is considered to not be a unit of syntax but a unit of semantics. According to Halliday and Hasan (1976), the concept of texture displays the feature of being a text. It is obvious that all languages have texts and so do certain linguistic features that create texture. Therefore, it can be concluded that any texture is made up of two different levels: the sentential and textual. Also, it should be reminded that the fundamental building blocks from which all texts are constructed are four independent components on the two aforementioned levels. The sentential level, on the one hand, is grammatical features of syntax at surface level representing semantics at deep structure. On the sentential level are syntax and semantics. Syntactic component involves types of phrasing, types of clause constructions, and types of passive structures, clausal combinations, and word order within a sentence. Semantic component involves the senses and mappings from word meanings to sentential meanings.

The textual level, on the other hand, is functional features of cohesion at surface level leading to coherence at deep structure. Grabe and Kaplan (1996) believed that cohesion and coherence are on textual level. This level is the underlying structure of the surface structure achieved through the use of grammatical elements to form the sentences and the first stage to the formation of the text through cohesion and coherence constructed on the basis of the textual cohesion through the readers' efforts to interpret. The relations between the sentences, at this level, play a major role in the achievement of coherence. Cohesion can be established by various means. These means include reference, substitution, ellipsis, conjunction, and lexical relationships. Based on the classification of the sub-categories by Halliday and Hasan (1976), reference can be grouped into four categories: pronominal, demonstrative, definite article 'the', and comparative. Substitution has been classified into four sub-categories, too: one/some/ones (as substitutes of noun phrases), do so/it/that (as substitutes of predicate), here/there/then (as substitutes of adverbials), and finally so/not (as substitutes of clauses). Ellipsis has been divided into three sub-categories: noun phrases, the predication, and a clause. The fourth is conjunction, which can be subcategorized into five: additive, adversative, causative, temporal and continuative. 
On the one hand, at the sentence level, analysis of cohesion provides a useful measure of the effectiveness and quality of written text. On the other hand, the analysis at textual level includes functional features of cohesion and coherence, which requires counting CDs such as reference, substitution, ellipsis, and conjunctions. To shed light on these issues, this study is an attempt to give readers an overview of the way EFL/ESL learners use CDs in writings, especially the expository, descriptive, and argumentative texts, to see which CDs and with how densely they are used to maintain text coherence and cohesion and produce relations between different parts of the text.

\section{LITERATURE REVIEW}

Recently, researchers have given considerable attention to how EFL/ESL learners write and what problems they encounter in writing a text. The construct of cohesion is one of the widely explored sub-fields of second language writing. By the application of Halliday and Hasan's (1976) framework, a great many of studies about cohesion and coherence in ESL/EFL writing and even in English itself (Jafarpur, 1991, Johns, 1980, Johnson, 1992; Zhang, 2000; Hartnett, 1989 cited in Johnson, 1992) have been done. Although some researchers came to similar findings, the findings of these studies in some cases have been somewhat contradictory. Some have found that there is no difference in the use of CDs in good and weak writings (Johnson, 1992; Zhang, 2000). Others showed that highly rated essays is different from low rated ones in the use of CDs (Jafarpur, 1991). Some researchers proved that highly scored compositions contain more cohesion than low scored ones (Jafarpur, 1991). Furthermore, it is commonly believed that highly scored essays include more lexical collocations than do low scored ones (Johns, 1980; Zhang, 2000). They also held that lexical cohesion is the most commonly used category in both good and weak essays, followed by conjunction and reference (Johns, 1980; Zhang, 2000).

In the writing of ESL/EFL learners, some peculiar features have also been identified (Olateju, 2006; Khalil, 1989; Wikborg, 1990; Dueraman, 2007). Olateju (2006) stated that some of the CDs were used wrongly or insufficiently and this may be associated to the insufficient direct exposure to the English and the misuse of these affected or even broke the coherence of the text. Irwin (1982) showed how mature readers use cohesion in text and showed that the increase in the number of CDs, in turn, can improve readers' comprehension. These studies explicitly bespoke that cohesion is a significant underlying feature of any type of writing and that L1 and L2 learners of English have considerable difficulty in applying CDs. Novice writers ten to one will use more CDs to produce a superficially logic text, but actually there may be no logicality in their writing.

Coherence, one of the influential features in judging the quality of a writing, has been considered to be a subjective and hazy concept which is hard to learn and teach (Crewe, 1990; Lee, 2002) in spite of the fact that cohesion and coherence being so intertwined are not easily distinguished and defined a separate entities. Lee (2002), as a writing teacher and researcher, also believed that the concept of coherence was not definite so that writing teachers had difficulties in teaching and assessing students' writing. Meanwhile, a number of researchers have defined coherence from different perspectives. However, as Grabe and Kaplan (1996, p. 67) stated, "there is little consensus on the matter of an overall definition of coherence". Castro (2004) defines coherence as the link in a text connecting ideas and making the flow of thoughts meaningful and clear for readers. So, it accounts for the meaningful and logical relationship among elements in a text, which stems from "thematic development, organization of information, or communicative purpose of the particular discourse" (Kuo, 1995, p.48). In Halliday and Hasan's definition in their book Cohesion in English (1976, p.23), coherence refers to the internal elements of a text, consisting of cohesion and register. They further added that "A text is a passage of discourse which is coherent in these two regards: it is coherent with respect to the context of situation, and therefore consistent in register; and it is coherent with respect to itself, and therefore cohesive".

Cohesion, based on Halliday and Hasan's (1976) cohesion theory as the major characteristic of coherence considering linguistic properties of the language, gives a sequence of sentences a coherent texture. Cohesion occurs where the interpretation of some elements in the discourse is dependent on that of another (Halliday \& Hasan, 1976). Halliday and Hasan (1976, p. vii) pointed out that cohesion is one of the linguistic system's major resources for text construction. In fact, cohesion represents the presence of explicit cues in the text that allow readers/listeners to find semantic relations within it as part of linguistic system enhancing the semantic potentials of text. A text is meaningful only when elements referring to each other in the text set up a relation. The relation can be set up through reference, substitution, ellipsis, and conjunction as grammatical and lexical cohesion. So, the grammar and lexicon are two forms of cohesion. These CDs used by speakers and writers in order to express meaning based on the interpretations of the listeners and readers provide semantic relations for the semantic units whose interpretations they facilitate.

Cohesion depicts how meaning-based relationship is set up by lexical and syntactic features. These explicit lexical and syntactic features are known as CDs, signaling the relationship in sentences and paragraphs. Halliday and Hasan (1976) introduced five different types of CDs in order to provide a guideline for studying and judging the cohesion and coherence of writing: (a) reference (i.e., the indication of information from elsewhere such as personals, demonstratives, and comparatives), (b) substitution (i.e., the replacement of one component by another), (c) ellipsis (i.e., the omission of a component), (d) conjunction (i.e., the indication of specific meaning which presupposes present items in the discourse, such as additive, adversative, casual, and temporal), and finally (e) lexical cohesion (i.e., the repetition of the same or 
relative lexical items). They contended that through analyzing the use of CDs, one could evaluate or assess writing quality from the perspective of coherence.

\section{Criticisms against the Cohesive Theory}

The cohesive theory proposed by Halliday and Hasan (1976) was challenged by Carrell (1982) and Johns (1986) who argued for the importance of readers' background knowledge. Based on schema theory, Carrell $(1982, \mathrm{p} .482)$ contended that "processing a text is an interactive process between the text and the prior background knowledge or memory schemata of the listener or reader". In other words, both the structure and content of the text and the readers' operation on the text should be taken into consideration. To support his criticisms of the cohesive view of coherence, Carrell (1982) meticulously scrutinized three empirical studies and claimed that there is no meaningful relationship between the number of CDs and coherence.

\section{THE ReLATIONSHIP BETWEEN THE USE OF CDS AND THE QUALITY OF L2 WRITING}

Zhang (2000) investigated the relative importance of various grammatical and discourse features in the evaluation of second language writing samples and found that raters heavily depended upon cohesion in evaluating the overall quality of the essays. This also pointed to the idea of considering CDs as an important element in judging the quality of essays. Lee (2002) investigated how CDs were used in the compositions of 107 Chinese undergraduates through both quantitative and qualitative methods. The research found that lexical devices were used most frequently, conjunctions and reference devices are used less and that certain CDs included ambiguity in reference, overuse and misuse of conjunctions, and restricted use of lexical cohesion. Lee (2002) did a research with 16 ESL students to reveal whether explicit teaching of coherence creating devices may contribute to the coherence in writing and found a positive relation between the pedagogical materials based on promoting the CDs and the improvement of the student writing. Zhang (2000) investigated the application of CDs in 50 argumentative compositions written by Chinese undergraduate nonEnglish majors and found that among a variety of CDs the lexical CDs were the most frequently employed, followed by references and conjunctives. And the number of lexical CDs was significantly related to the quality of writing. However, it was identified that there were some problems in applying reference and lexical devices. One other research by Olateju (2006) investigated to what extent ESL learners achieve cohesion in written texts by examining students at different writing sessions. The study revealed that the students lacked competence in their use of CDs. In the study on cohesion on oral English, Wu (2006) found that substitution and ellipsis are neglected and less used forms of CDs. It was also clarified that foreign language learners probably use such devices less even in their oral performance, which is in contrast to what is commonly thought. Field and Yip (1992) in Hong Kong examined the use of three types of CDs, say, reference, conjunction, and lexis in essays of 150 foreign language learners referring to their narrative and descriptive essays. They found that the three easiest writing devices were remote CDs, immediate CDs, and mediate CDs and the three hardest writing devices were temporal conjunctions, causal conjunctions, and adversative conjunctions. Several studies have indicated the problems that L2 writers have while writing (Crewe, 1990; Kanno, 1989; Wu, 2006).

\section{NATives' Writings in CONTRAST to ThOSE OF NONNATiVeS}

According to Khalil (1989), the Arab students overused reiteration of the same lexical item as a cohesive device, while they underused other lexical and grammatical CDs. With regard to incoherent writings of Hong Kong college students, Crewe (1990) recognized two problems: using numerous connectives without discerning the semantic differences among them, such as using on the contrary instead of however, and overusing connectives. Wikborg (1990) found that Swedish students often showed cohesion problems ranging from missing or misleading sentence connection to too great a distance between the cohesive items in a cohesive chain to malfunctioning CDs in their writing. Johnson (1992) proved that there was not any difference in the degree of cohesion between good and weak compositions written in Malay by native speakers or in English by native and Malay speakers. Comparing 67 Hong Kong students' argumentative writings with those of 29 Australian students in English, Field and Yip (1992) concluded that Hong Kong students used more conjunctions especially at the beginning of sentences. With regard to Palmer's (1999) survey, the writings of Spanish-speaking students abound in reiteration of the same lexical item as a cohesive device, but other lexical and grammatical CDs were rare. This is the case considering Zhang's (2000) findings on Chinese undergraduate English majors. Zhang (2000) in the survey of cohesion in 107 Chinese English majors' expository essays found that there was no difference in the number of CDs between good and weak essays. Dueraman's (2007) study about cohesion and coherence in English narrative essays written by Malaysian and Thai medical students also explicitly supported the fact that both groups used more syntactic ties (reference and conjunction) than semantic ties (reiteration and collocation).

\section{CORRELATION BETWEEN CDS AND QUALITY OF WRITING}

There are both positive and negative correlation between the use of CDs and the quality of writing. To shed light on the construct of coherence and the relationship between cohesion and coherence, empirical studies that investigated the correlation of the use of CDs and the overall quality of writing have been reviewed and it was found that the studies contained controversial results. On the one hand, some studies proved a positive correlation between the number of CDs 
and good writing (Ferris, 1994; Field \& Oi, 1992; Jin, 2001; Liu \& Braine, 2005). On the other hand, other studies have not shown a significant link between the number of CDs and the quality of writing (Castro, 2004; Jafarpur, 1991; Johnson, 1992; Neuner, 1987; Zhang, 2000). Among the studies, two studies (i.e., Liu \& Braine, 2005; Zhang, 2000) were conducted in China and one in Iran (Jafapur, 1991).

\section{A. Research on CDs Based on Frequency of CDs Used in the Students' Writing}

These studies concentrated on the frequency of DMs used in the learners' writing, some investigating the use of DMs in one language (L1 or L2) and others comparing the frequency of the use of DMs between L1 and L2. For example, Connor (1984) contrasted six argumentative essays written by English native and ESL learners based on Halliday and Hasan's (1976) framework. Any major difference was found between native and ESL students in the frequency of DMs. The writings of 67 Hong Kong students with 29 Australians on an argumentative topic were compared by Field and Yip (1992). They proved that non-native learners of English used more conjunctions than Australians and they usually put all conjunctions at the beginning of sentences. In a study of this type, comparing the number of DMs used by native and non-native speakers of English, Karasi (1994) scrutinized 135 expository essays by Singaporean secondary students. They showed no difference between native and ESL students in the frequency of CDs. Intarprawat and Steffensen (1995) dissected the DMs used in persuasive essays by ESL university students. They unraveled that differences between highly and poorly rated essays were found in the number of words, T-units, and density of DMs. That is, the former was characterized by a high density of these features. A study by Steffensen and Cheng (1996) concentrated on argumentative texts written by students working on the propositional content of their essays and being taught using a process approach and focusing on the pragmatic functions of DMs by enjoying direct teaching of DMs. The results showed that students receiving direct instruction on DMs used them more effectively and also became more sensitive to their readers' needs, thereby making global changes that improved their papers. Jalilifar (2008) following Fraser's (1999) classification of DMs focused on DMs in descriptive compositions of 90 junior and senior Iranian EFL students. Findings of the research provided evidence that elaborative markers were the most frequently used, then inferential, contrastive, and causative and least frequently used are topic relating markers. A direct and positive relationship was also found between the quality of the compositions and the number of DMs used.

\section{B. Research on DMs Based on the Nature of DMs Used in Students' Writing}

This group of studies has put the nature of DMs used in students' writing under the microscope. Liu and Braine (2005), based on Haliday and Hassan's (1976) taxonomy of CDs, dissected the use of CDs in 50 Chinese undergraduate non-English majors' argumentative compositions and examined the relationship between the number of CDs and the quality of writing. Among the sub-categories of conjunction devices, additive, causal, temporal, and adversative devices were used in decreasing order. 'And', 'also', and 'or' were the cohesive items with the highest frequency. Among adversative devices, 'on the contrary' and 'instead' occurred very little in their writings, while, 'but' was used with the highest frequency. Other items such as 'as a result' and 'thus' were rarely used. Using frequency counts, Hu, Brown, D., and Brown, L. (1982), investigated the use of CDs by 12 Chinese university students in contrast to 12 Australian university students based on the Halliday's functional grammar. They proved that Chinese used more conjunctions and Australians used more lexical cohesion. Bell (2010) scrutinized the contrastive DMs of 'nevertheless', 'still', and 'yet' by focusing on an 8 million-word corpus of fiction, news, and academic spoken and written English. The results proved 'nevertheless' to be the most limited scope and 'yet' the largest scope. Hays (1992) put the use of DMs by Japanese learners of English in their first, second, or third year of study under the microscope and found that though DMs 'but', 'and', and 'so' were used frequently, very few learners used 'well' and 'you know' and speculated that there is a developmental order for the acquisition of DMs. That is, the DMs which are on the ideational plane are taught and used earlier than those that are more pragmatic in the subjects' speech. This fact was supported by the findings of Trillo's (2002) corpus based study comparing DMs usage between native speakers and learners of English. Trillo (2002) demonstrated that learners of English used the DMs 'well' and 'you know' (among others) much less frequently than native speakers and that when learners used these lexical items, they were much more likely to be in their ideational, non-pragmatic usages.

\section{Research on the Relationship between DMs and Writing Quality}

The studies in this sub-section investigated the correlation of DMs and writing quality. Allard and Ulatowska (1991), based on Halliday and Hasan's (1976) framework, analyzed the writings of 30 fifth-grade native English children and found a high relationship between the number of lexical ties and the quality of writing. Narrative and procedural texts were used and found that for narratives, but procedural texts, CDs were highly correlated with writing quality and there were marked differences in cohesive properties across discourse types. Zhang (2000) concentrated on the use of CDs in Chinese undergraduates' expository compositions, 107 essays from two universities, based on Halliday and Hasan's (1976) taxonomy of CDs and their framework and proved that students employed a variety of CDs with some categories of ties used more frequently than the others, lexical devices were the most frequently used, followed by conjunctions and reference devices. There found not to be statistically significant relationship between the number of CDs and the quality of writing. Certain CDs were identified in the expository writing of Chinese undergraduates which included overuse and misuse of conjunctions and restricted use of lexical cohesion. Liu and Braine (2005), to analyze the 
relationship between the number of CDs and writing quality in argumentative compositions written by Chinese undergraduate EFL learners, did a correlational survey between the numerical composition scores and the frequency of CDs in every composition with regard to their categories (reference, conjunction, and lexical cohesion). The findings showed that the composition scores significantly correlated with the number of CDs, highly correlated with lexical devices among the three main categories of CDs. Johnson (1992) investigated expository essays in Malay, essays in English by the same group of Malay students, and essays in English by native speakers, each 20 but did not find any difference in the degree of cohesion between good and weak compositions written in Malay by native speakers or in English by native and Malay speakers. Generally speaking, results suggested that L2 learners compared to native speakers underuse DMs.

\section{Research on the Relationship between DMs and Writing Genres}

Both being acquainted with different writing genres and being familiar with the internal features of written texts can affect learners' writing quality to a large extent. The notion of genre is defined as "abstract, socially recognized ways of using language" (Hyland, 2003, p. 21) which are purposeful communicative activities applied by members of a particular discourse community (Swales, 1990). Here some writing genres and the correlation of genre and use of CDs will be briefly discussed.

Argumentative writing as a fundamental writing style is required in higher education to compose various types of writings, to pursue the goal of convincing an audience. Where there exists a conflict between the beliefs and attitudes of the writer/speaker and the reader/audience, this type of writing genre is often used in a situation (Hinkel, 2002). Based on Halliday and Hasan's (1976) framework, Connor (1984) compared six argumentative essays written by English native and ESL learners. There found to be not any significant difference between native and ESL students in the frequency of DMs. Field and Yip (1992) analyzed and compared the argumentative writings of 67 Hong Kong with 29 Australians. They pointed out that nonnative learners of English used more conjunctions than Australians and nonnatives usually use all conjunctions at the beginning of the sentences. Using the same framework, Liu and Braine (2005) investigated the use of CDs in 50 argumentative compositions written by Chinese undergraduate non-English majors and also critically dissected the relationship between the number of CDs and writing quality.

Descriptive writings, on the other hand were widely used by English learners and users to explain and describe the events etc. Jalilifar (2008), according to Fraser's (1999) classification of DMs, focused on DMs in descriptive compositions of 90 Iranian EFL juniors and seniors. Results proved that elaborative markers were the most frequently used DMs, inferential, contrastive, and causative markers are descending in terms of frequency, and topic relating markers are least frequently used). There found to be a direct and positive correlation between the quality of the compositions and the number of DMs used.

Expository writing is the other genre of writing used frequently by ESL/EFL learners and users. Johnson (1992) dissected 20 expository essays in the country Malay and 20 essays in English by the same group of Malay students and 20 essays in English by native speakers. There found to be no significant difference in the degree of cohesion between good and weak compositions written by native speakers in Malay or in English by native and Malay speakers. Generally speaking, findings suggested that L2 learners underuse DMs compared to the native speakers especially for their pragmatic functions. Karasi (1994) comparing the frequency of DMs used by native and non-native speakers of English, analyzed 135 expository essays composed by Singaporean secondary students and pointed out that there is no difference between native and ESL students in the frequency of CDs. In a similar study, Zhang (2000) concentrated on the application of CDs in the expository compositions of 107 Chinese undergraduates from two Chinese universities. Halliday and Hasan's (1976) taxonomy and framework were utilized. A variety of CDs were used by the students. Some categories of ties were used more frequently than the others. Lexical devices were the most frequently used, followed by conjunctions and reference devices were used least frequently. Findings showed no statistically significant relationship between the number of CDs and the quality of students' writings. Some CDs were misused or overused in the expository writing of Chinese undergraduates.

\section{Significance OF THE StUdy}

Lexical items, as the main carrier of message and the means of expression, are the major building blocks of any composition. The fact that lexical devices are the most broadly used may affect cohesion in language users' writings. As mentioned earlier, language learners are able to apply a variety of conjunctive devices to bridge the previous and following sentence(s) both to make their writing more clear, orderly, and logical and to make their writings semantically, pragmatically, and grammatically well formed. Although, only those commonly used items as and, but, however, also, first, second, and conclusion were the students' favorites, the items learned later such as furthermore, on the contrary, moreover, in addition, on the whole, and nevertheless seldom occurred in their writing. As a consequence, much needs to be done in the teaching of writing to enhance the students' awareness of the importance and use of CDs in their writing.

Widdowson (1983) believed that enough attention has not been paid to the way in which sentences are used in combination in order to form stretches of connected discourse. This connotes that in the classroom settings, the teachers look at language as essentially knowledge of the syntactic structure of sentences. In fact, students face difficulty coping 
with language in its normal communicative use. This problem requires a new orientation both in teaching and research. Hymes (1971) suggested that there should be a shift from grammatical competence to emphasis on the discourse skills. This new orientation imposes a change of focus from the sentence as the basic unit of study to the use of a series of sentences in a discourse. In sum, a need to study the nature of discourse has been felt recently. Writing in English is being felt to be more important thanks to the fact that even EFL learners have to write papers and theses in English, and also send job application letters and economic activities on an international scale. So, the role of English language in international communications has been magnified (Arvani, 2006).

\section{THE QUESTIONS UNDER INVESTIGATION}

Since it is the sentence rather than the text as a whole, that has received the primary focus (Johns, 1980) and on the other hand, cohesion is important both to the reader and writer to create and comprehend a text (Halliday \& Hasan, 1976), so more attention should be paid to writing generally and to the role of CDs particularly. Sticking to Halliday and Hasan's (1976) cohesion theory as the most frequently used framework, the reviewed studies seek to identify the general CDs in writing composed by EFL/ESL learners. It aims to answer the following questions:

1. Do the learners use CDs in their writing? To what extent? Which category of CDs?

2. What is the relationship between the number of CDs and the scores of the same compositions?

3. What is the correlation in frequency of CDs within different categories of cohesion produced in the compositions? To what extent does the use of CDs influence the quality of writings?

4. What is the difference in the frequency of using CDs between highly-rated and poorly-rated compositions? Is there any relationship between the number of CDs and good writing?

5. What is the difference in the frequency of CDs among different genres of writings? Is there a significant difference between the DMs used in different types of genres?

6. What problems do language users face while using CDs?

7. Is there a quantitative difference between the L1 writing samples and L2 writing samples at the sentential level?

8. Is there a difference in the L2 writers' use of CDs compared to those of native writers?

\section{THEORETICAL FRAMEWORK OF THE STUDY}

This study, on the one hand, was based on the Fraser's (1999) taxonomy of DMs categories. In contrast to the similar taxonomies of CDs, this typology is mainly used for the classification of written discourse and seems to be the most comprehensive classification in written discourse. Fraser (1999) defined DMs as a pragmatic class, lexical expressions drawn primarily from the syntactic classes of conjunctions, adverbials, and prepositional phrases. In accordance with the proposed model, there are two types of DMs: (a) Those that relate aspects of the explicit message conveyed by S2 with aspects of a message, direct or indirect, associated with S1, and (b) Those that relate the topic of S2 to that of S1. Fraser's (1999) taxonomy includes six main subclasses. These subcategories are presented below: (a) conclusive DMs: in sum, in conclusion, to sum up, etc., (b) reason DMs: because, since, due to, etc., (c) elaborative DMs: and, also, moreover, in addition, etc., (d) contrastive DMs: but, however, although, etc., (e) inferential DMs: thus, hence, so, therefore, etc., and finally (f) exemplifiers: for example, such as, for instance, etc.

On the other hand, according to Halliday and Hasan's cohesion theory (1976), cohesion, as the major characteristic of coherence covering linguistic properties of the language, gives a sequence of sentences a coherent texture. Cohesion shows how semantic relationships are set up by lexical and syntactic features. Such overt lexical and syntactic features are called CDs, which signal the relationship among sentences. To provide a framework for studying and judging the cohesion and coherence of writing, Halliday and Hasan (1976) introduced five different types of CDs: (a) reference (i.e., the indication of information from elsewhere such as personals, demonstratives, and comparatives), (b) substitution (i.e., the replacement of one component by another), (c) ellipsis (i.e., the omission of a component), (d) conjunction (i.e., the indication of specific meaning which presupposes present items in the discourse, such as additive, adversative, casual, and temporal), and finally (e) lexical cohesion (i.e., the repetition of the same or relative lexical items). They contended that through analyzing the use of cohesive device, one could evaluate or assess writing quality from the perspective of coherence.

\section{Pedagogical Implications}

The present study, based on the findings and discussions illustrated above, provided some suggestions for both writing teachers and EFL/ESL learners. Firstly, since the number of CDs affects the quality of writing, "cohesion is not coherence" (Carrell, 1982) could be realized. So, a composition with more CDs cannot be considered as a coherent one. Therefore, when teachers are teaching their students how to use CDs, it is worth reminding that a proper dose of CDs makes writing better.

Secondly, since the findings indicated that the participants preferred repeating words rather than using synonyms and antonyms to describe the main points of their topic, teachers should help students enlarge their choice of vocabulary. Teachers could engage the students in some vocabulary activities such as word association game before writing to elicit and build students' vocabulary. 
Thirdly, writing teachers could introduce corpora to students since corpora can enhance learners' awareness of lexico-grammatical patterning of texts (Thurstun \& Candlin, 1998; Yoon, 2008). Corpus-informed syllabi can be mixed with writing courses wherein students learn to solve their lexical problems through concordances and collocation samplers.

Fourthly, learners did not apply a vast range of CDs and that they used some particular elaborative markers like and in higher than other markers and overuse of and can be a sign of weakness on the part of these learners in their writings. This denotes that teachers can work more on incorporating the use of DMs in their teaching. In other words, teachers need to raise the students' awareness of textual norms of practice and sensitize them to the application of specific CDs and their frequency in particular types of texts. Therefore, the learners will undoubtedly learn how to produce texts with different purposes and structures, and which types of DMs are more commonly used in which particular text types, when writing in English.

Fifthly, the rarity of the relationship between writing quality and the use of cohesive devices can connote that their use has not been done appropriately and purposefully by EFL/ESL learners. Therefore, teachers can work not only on the quantity of CDs but also on their quality. It is needed to raise the learners' awareness of the correct use of individual categories of CDs and how they can be used in creating a coherent text. It is also needed to let the learners realize CDs are not the mere textual devices which can add to the quality of a text, rather, there are other elements that making a text more cohesive and thus adding to the quality of the texts.

Last but not least, it is essential to incorporate reading into writing in order to enhance students' awareness of coherence and cohesion (Heller, 1999; Hirvela, 2004). Students can acquire syntactic structures, features of genre, or vocabulary through the process of reading to write. What's more, observing the use of CDs can also enhance students' awareness of the characteristics of good English writing. It is expected that the suggestions briefly mentioned above could improve students' writing skills and promote writing teachers' teaching quality.

\section{CONCLusion}

Based on the findings, it can be concluded that some CDs were more preferred than some others for a variety of reasons. This dynamic nature in the use of CDs could be contributed to the nature of the data collection procedure since some CDs belong to the conversational data in oral performance. The other reason might be minimal amount of knowledge and necessary discourse in which such structures are used. Also, it could be related to this fact that language learners lack the ability to use syntactic and lexical tools to enable them to produce competent written text as also indicated by Hinkle (2008). There are cross linguistic differences in the use of CDs by native and nonnative learners. Findings proved that language users resorted to pronominal more than other CDs in order for creating textuality between the sentences. There might be some other reasons for the distinct differences between the natives and nonnatives in the use of certain CDs on account of cross-linguistic differences. On the one hand, it could be emanated from the lack of nonnatives' English language proficiency, especially, because nonnatives may lack knowledge of what makes a written material a meaningful English text. This may be resulted from little exposure to or insufficient feedback, which in turn lead to little knowledge of how language users connect sentences to create textuality. So, they lack the competence in producing linguistically well-formed written material to create meaningful texts that convey the information appropriately and accurately as well as coherently. On the other hand, these difficulties could also be due to the linguistic knowledge of English they have been offered so far. They may have been taught by inexperienced teachers with limited discourse knowledge and experience in teaching cohesion and coherence. As far as language acquisition is concerned, it was stressed that it is not enough to look at input and to look at frequency of occurrences. Instead, looking at the corpus as a whole and examining discourse to determine both the frequency of forms and how it shows language function evolving is of value. This implies the trend from a product-oriented view to a process-oriented view of second language acquisition.

\section{LIMITATIONS}

This study was based on the collected data from the written discourse of native and nonnative learners, expecting that this could reveal the CDs they choose to use in their writings. However, the uses of CDs vary in the mode of communication, written or oral. Some CDs are used in verbal communication while some others are in written communication. Therefore, data could have been collected from oral performances of both native and nonnative learners in EFL/ESL situations to provide better picture of the ways CDs are used. Another limitation is the limited number of the studies reviewed by the researcher judging about the cohesion quality of the sample writings. More studies could yield a more reliable result of the use of CDs. Further, the reviewed studies had not been exactly corresponded to what Halliday and Hasan (1976) introduced because some researchers focused on some perspectives of their framework and ignore other ones. The main reason for excluding some and including the others may be that writers' production considerably depends on the quality and competence of the vocabulary development. And the vocabulary potential of each natives and nonnatives may vary remarkably depending on various factors. 


\section{REFERENCES}

[1] Allard, L., \& Ulatowska, H. K. (1991). Cohesion in written narrative and procedural discourse of fifth-grade children. Linguistics and Education, 3, 63-79.

[2] Arvani, M. (2006). A discourse analysis of business letters written by Iranians and native speakers. The Asian ESP Journal, 1 , $12-22$.

[3] Bell, D. M. (2010). Nevertheless, still, and yet: Cohesive cancellative discourse markers. Journal of Pragmatics, 42, $1912-1927$.

[4] Carrell, P. L. (1982). Cohesion is not coherence. TESOL Quarterly, 16 (4), 479-488.

[5] Castro, C. D. (2004). Cohesion and the social construction of meaning in the essays of Filipino college students writing in L2 English. Asia Pacific Education Review, 5 (2), 215-225.

[6] Connor, U. (1984). A study of cohesion and coherence in English as a second language students' writing. Papers in Linguistics: International Journal of Human Communication, 17, 301-316.

[7] Crewe, W. J. (1990). The illogic of logical connectives. ELT Journal, 44 (4), 316-325.

[8] Dueraman, B. (2007). Cohesion and coherence in English essay written by Malaysian and Thai medical students. Retrieved June 5, 2013, from http://fs.libarts.psu.ac.th/webcontent/Document/Doc2550/01January/ research2007/LanguagesAndLinguistics/Cohesion\%20and\%20Coherence\%20in\%20English\%20...Bayatee.pdf.

[9] Ferris, D. R. (1994). Lexical and syntactic features of ESL writing by students at different levels of L2 proficiency. TESOL Quarterly, 28 (2), 414-420.

[10] Field, Y., \& Yip, L. (1992). A comparison of internal conjunctive cohesion in the English essay writing of Cantonese speakers and native speakers of English. RELC Journal 23, 15-28.

[11] Field, Y., \& Oi, Y. (1992). A comparison of internal cohesive conjunction in the English writing of Cantonese speakers of English. RELC Journal, 23, 15-28.

[12] Fraser, B. (1999). What are discourse markers? Journal of Pragmatics, 31, 931-952.

[13] Grabe, W., \& Kaplan, R. B. (1996). Theory and practice of writing: An applied linguistics perspectives. London: Longman.

[14] Halliday, M. A. K., \& Hasan, R. (1976). Cohesion in English. London: Longman.

[15] Halliday, M. A. K., \& Hasan, R. (1989). Language, context, and text: Aspects of language in a social-semiotic perspective. (2nd Ed.). Oxford: Oxford University Press.

[16] Hays, P. (1992). Discourse markers and L2 acquisition. Papers in Applied Linguistics, 7, 24-34.

[17] Heller, M. F. (1999). Reading-writing connections: From theory to practice. (2nd Ed.). NY: Longman.

[18] Hinkel, E. (2002). Second language writers' text. Mahwah, NJ: Lawrence Erlbaum.

[19] Hinkle, E. (2008). Teaching grammar in writing classes. In E. Hinkle, \& S. Fotos (Eds.), New perspectives on grammar teaching in second language classrooms (pp. 150-198). New York: Routledge.

[20] Hirvela, A. (2004). Connecting reading and writing in second language writing instruction. Ann Arbor, MI: University of Michigan Press.

[21] Hu, Z., Brown, D., \& Brown, L. (1982). Some linguistic differences in the written English of Chinese and Australian students. Language Learning and Communication, 1, 39- 49.

[22] Hyland, K. (2003). Genre-based pedagogies: A social response to process. Journal of Second Language Writing, 12, 17-29.

[23] Intarparawat, P., \& Steffensen, M. S. (1995). The use of meta-discourse in good and poor ESL essays. Journal of Second Language Writing, 4, 253-272.

[24] Irwin, J. W. (1982). Cohesion and comprehension. Illinois Reading Council Journal. Newark, Delaware: International Reading Association.

[25] Jafarpur, A. (1991). Cohesiveness as a basis for evaluating compositions. System, 19 (4), 459-465.

[26] Jalilifar, A. R. (2008). Discourse markers in composition writings: The case of Iranian learners of English as a foreign language. English Language Teaching, 1, 114-127.

[27] Jin, W. (2001). A quantitative study of cohesion in Chinese graduate students' writing: Variations across genres and proficiency levels. Paper presented at the Symposium on Second Language Writing at Purdue University (West Lafayette, Indiana, September 15-16, 2000).

[28] Johns, A. M. (1980). Cohesion in written business discourse: Some contrasts. The ESP Journal, 1 (1), 35-44.

[29] Johns, A. M. (1986). Coherence and academic writing: Some definitions and suggestions for teaching. TESOL Quarterly, 20 (2), 247-265.

[30] Johnson, P. (1992). Cohesion and coherence in compositions in Malay and English. RELC Journal, 23 (2), 1-17.

[31] Kanno, Y. (1989). The use of connectives in English academic papers written by Japanese students. Psycholinguistics, 2, 41-54.

[32] Karasi, M. (1994). Cohesive features in the expository essays of Secondary Four (Express) and Secondary Five (Normal) students in Singapore. Unpublished master's thesis, Nanyang Technological University, Singapore.

[33] Khalil, A. (1989). A study of cohesion and coherence in Arab EFL collage students' writing. System, 17, 359-371.

[34] Kuo, C. H. (1995). Cohesion and coherence in academic writing: From lexical choice to organization. RELC Journal, $26,47-62$.

[35] Lee, I. (2002). Teaching coherence to ESL students: A classroom inquiry. Journal of Second Language Writing, 11, 135-159.

[36] Liu, M., \& Braine, G. (2005). Cohesive features in argumentative writing produced by Chinese undergraduates. System, 33, 623-636.

[37] Neuner, J. L. (1987). Cohesive ties and chains in good and poor freshman essays. Research in the Teaching of English, 21 (1), 92-105.

[38] Olateju, M. A. (2006). Cohesion in ESL classroom written texts. Nordic Journal of African Studies, 15 (3), $314-331$.

[39] Palmer, J. C. (1999). Coherence and cohesion in the English language classroom: The use of lexical reiteration and pronominalisation. RELC Journal, 30, 61-85.

[40] Richards, J. C., \& Renandya, W. A. (2002). Methodology in language teaching: An anthology of current practice. Cambridge: Cambridge University Press. 
[41] Steffensen, M., \& Cheng, X. (1996). Meta-discourse and text pragmatics: How students write after learning about metadiscourse. ERIC Document Reproduction Service, No. ED400709.

[42] Swales, J. M. (1990). Genre analysis: English in academic and research settings. Cambridge: Cambridge University Press.

[43] Thurstun, J., \& Candlin, C. (1998). Concordancing and the teaching of the vocabulary of academic English. English for Specific Purposes, 17 (3), 267-280.

[44] Trillo, J. R. (2002). The pragmatic fossilization of discourse markers in non-native speakers of English. Journal of Pragmatics, 34, 769-784.

[45] Widdowson, H. G. (1983). Learning purpose and language use. Oxford: Oxford University Press.

[46] Wikborg, E. (1990). Types of coherence breaks in Swedish student writing: Misleading paragraph division. In: U. Connor and A. M. Johns (Eds.), Coherence in writing: Research and pedagogical perspectives, TESOL, Alexandria, VA, pp. 131-148.

[47] Wu, S. R. (2006). Connectives and topic-fronting devices in academic writing: Taiwanese EFL student writers vs. international writers. 2006 International Conference and Workshop on TEFL and Applied Linguistics, 417-425.

[48] Yoon, H. (2008). More than a linguistic reference: The influence of corpus technology on L2 academic writing. Language Learning and Technology, 12 (2), 31-48.

[49] Zhang, M. (2000). Cohesive features in the expository writing of undergraduates in two Chinese universities. RELC Journal, 30 (1), 61-95.

Mohsen Ghasemi, graduated from Ferdowsi University-Mashhad-Iran. He has been teaching in Mashhad IELTS Center for 8 years. He has published more than 20 books in the related filed. He has also published some papers in accredit journals and presented in conferences both nationally and internationally. 